\title{
Ultrastructural Signs of Regenerative-Degenerative Processes in Long-Term Dentate Fascia Grafts
}

\author{
Z.N. Zhuravleva \\ Institute of Theoretical and Experimental Biophysics, Russian Academy of Siciences \\ Puschino-on-Oka, Moscow, 142292, Russia
}

SUMMARY

An ultrastructural investigation of embryonic (E20) dentate fascia grafts transplanted into an acute cavity in the somatosensory neocortex of adult rats revealed a continuous dynamic state of the tissue nine months postgrafting. The grafts consisted mainly of typical granular cells with some admixture of hippocampal pyramidal neurons and polymorph hilar cells with a normal, mature ultrastructure. Many features of the transplanted tissue suggested continuing development and growth. Dendritic branches with growth tips, axonal growth cones, synaptic boutons with growth vesicles, immature myelin sheaths and myelin-producing cells were observed. In contrast, ultrastructural signs of degeneration were present in some axons, and, less often, in dendrites. These processes, as well as some of the terminal synapses, contained various amounts of lysosomes and lipofuscine granules. In many such terminals the signs of degenerative change were combined with the presence of multiple mitochondria, polymorph vesicles and tubular reticulum, indicating simultaneous reparative processes. It is suggested that continuous recycling of neuronal processes occurs in longterm dentate grafts. This morphological instability may depend on the paucity of synaptic targets within the dentate tissue transplanted with a minimal quantity of hippocampal pyramidal cells and on the limitation of the afferent input. However, the observed features of the grafted dentate tissue are not qualitatively different from those observed in normal dentate with its protracted development and active compensatory reorganization.

\section{KEY WORDS}

dentate fascia, intracortical transplants, neuronal processes, synapses, growth, degeneration

\section{INTRODUCTION}

In previous papers $/ 40,41 /$ we have shown that embryonic dentate fascia heterotopically grafted into the primary somatosensory neocortex (barrel field) of adult rats develops reciprocal connections with surrounding host tissue and that typical giant synaptic boutons of the mossy fibers establish contacts with neocortical neurons. The present paper describes some ultrastructural features of the grafted dentate tissue itself after long-term (nine months) survival in the host neocortex. Normal development and expression of organotypic characteristics by dentate fascia tissue have been described by many authors in homotopic (intrahippocampal) $/ 22,26 /$, heterotopic $/ 33 /$ and intraocular $/ 15,26 /$ dentate grafts. A detailed description of the ultrastructure of the dentate fascia grafts will therefore not be presented in this paper. While our data generally support the conclusions of these authors concerning the normal cellular composition of the grafts, certain ultrastructural features suggest a dynamic state of the grafted tissue in spite of its long-term survival in the host brain. Signs of both developmental and degenerative changes indicate a continuous recycling process in the grafted nervous tissue.

\section{MATERIALS AND METHODS}

A detailed description of the methods has been presented by us previously /40,41/. Embryonic (E20) dentate fascia tissue was dissected from the 
hippocampal anlage and placed into a cavity produced by aspiration of the neocortical barrel field of young adult (3 months) male Wistar rats $(n=11)$. Nine months postgrafting the pieces of the neocortex containing dentate grafts were prepared for standard electron microscopic investigation. The central and peripheral areas of the grafts were analyzed under a Tesla BS513 electron microscope.

\section{RESULTS}

The granular cells constituted the main neuronal elements of the grafted tissue. However, a certain number of pyramidal neurons, inadvertently taken during the dentate anlage dissection from the hippocampus proper, were also present in the grafts. In addition, some polymorph cells with osmiophilic cytoplasm and deeply invaginated nuclei were encountered among the neuronal elements. All cells were easily identified by their dimensions and the details of their ultrastructural organization.

Some unusual features could be detected in the grafted cells. The cytoplasmic membranes of the granular cells, which normally have smooth rounded contours, were often indented and had various protuberances and filopodia. These appendages contained fuzzy material, but in some of them ribosomes and polysomes could be detected; microtubules never entered them (Fig. 1A). Such rough contours of cytoplasmic membrane were observed especially often in the dispersed granular cells, situated out of their dense clusters. Large perikarya of the pyramidal neurons also had similar protuberances and indentations of their surface membranes. Sometimes invaginations of the somatic membrane filled up by neuropil elements were so deep that in some sections they looked like neuropil islets, surrounded by neuronal cytoplasm (Fig. 1B).

The dendritic system of the grafted neurons was well developed. Proximal segments of dendrites contained numerous cytoplasmic organelles. Their distal branches had many spines with active zones. Detailed analysis revealed evidence of continuing development. Some dendrites, besides typical spines, had cytoplasmic filopodia. Short thin branchlets were seen leaving the parent dendrites

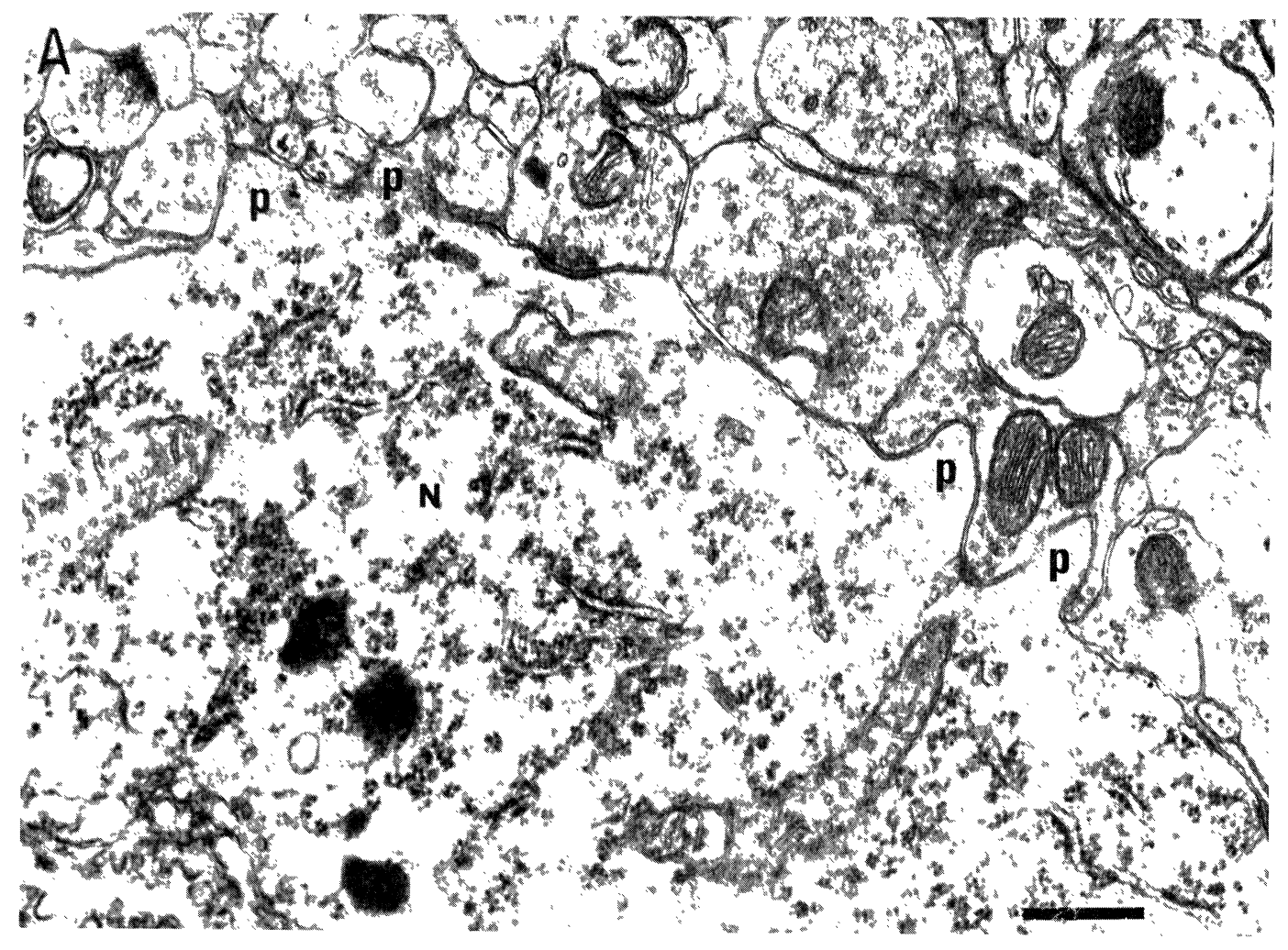

Fig. 1. 

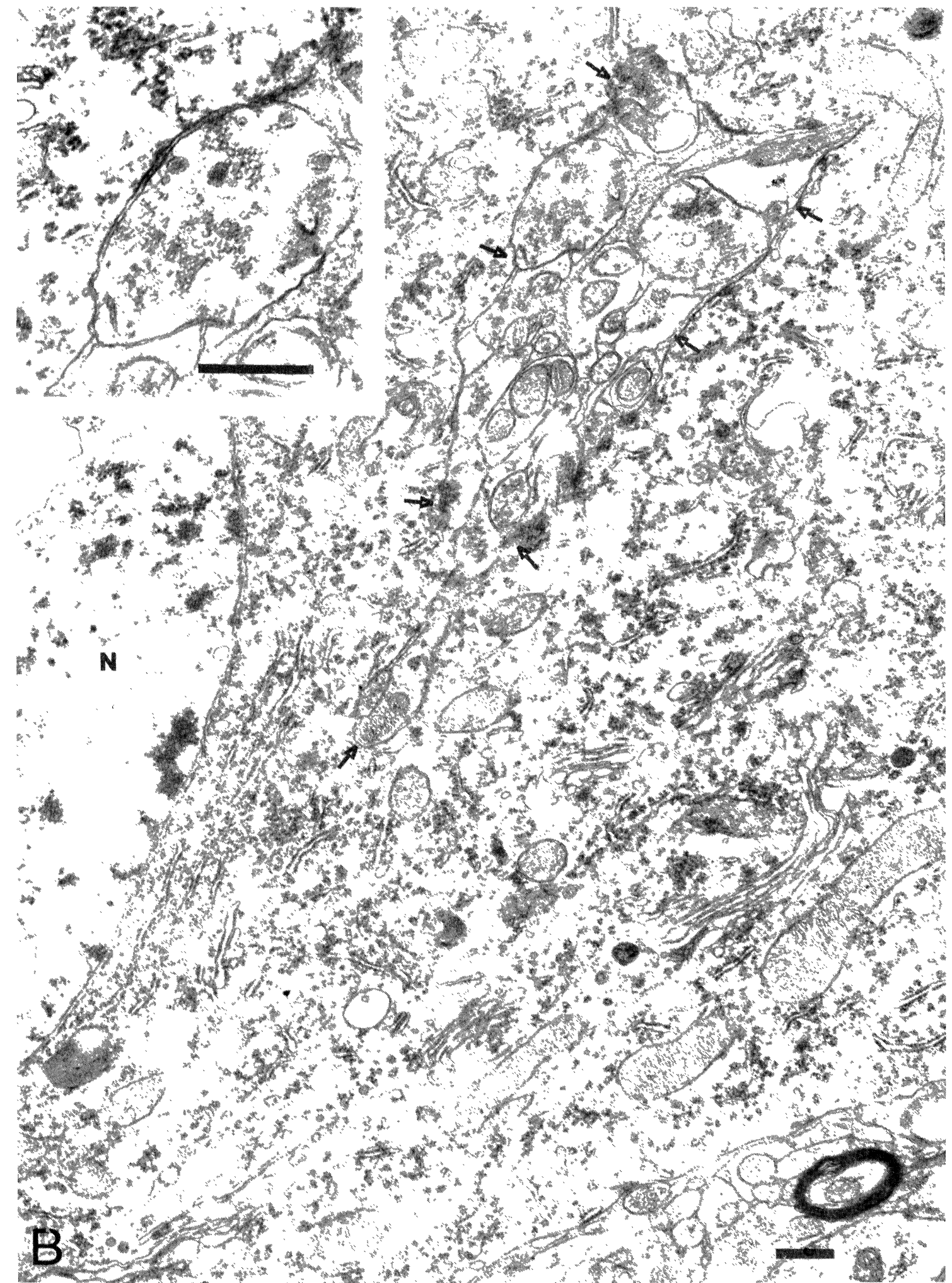

Fig. 1: Rough surface of the neuronal somata in the grafted tissuc. A. A granular ncuron $(\mathrm{N})$ with cytoplasmic protuberances (p) on its surface. Bar $0.5 \mathrm{~mm}$. B. One of the few pyramidal neurons of the graft $(\mathrm{N})$ with deep invagination of the cytoplasmic membrane containing an islet of ncuropil (arrows). Vacuoles are present in the nucleus. A symmetric synaptic contact from the islet is shown at larger magnification in the inset at the left upper corner. Bar $0.5 \mathrm{~mm}$. 
and terminating in growth tips which contained the cytoplasmic organelles responsible for metabolic processes (ribosomes, cisterns of endoplasmic reticulum, and mitochondria) (Fig. 2A). Some postsynaptic active zones had no corresponding accumulations of synaptic vesicles on the presynaptic side (Fig. 2B).

Continuing development could also be traced in axons of the grafted neurons. Some axons terminated in typical growth cones (Fig. 2C). The majority of the myelinated axons had mature, compact myelin sheaths. However, some axons with still developing, loose myelin were also encountered (Fig. 3A). They were more often present in peripheral areas of the graft, close to the interface with the host brain. Some myelin-producing cells in the graft had electron-lucid cytoplasm, typical of immature oligodendrocytes. The direct transition between the cytoplasmic processes of such cells and the outer layer of the myelin sheath could be traced (Fig. 3B). Additional thin lammellar cytoplasmic processes of the glial cells were seen to envelop the myelinated axons. Identification of such glial cells at the ultrastructural level was difficult. It is possible that these cells represent immature oligodendrocytes, but the possibility that they are astrocytes participating in myelinization cannot be excluded

The density of synaptic contacts varied in different parts of the grafts from medium to high. Some dendrites were literally studded with closely apposing synaptic boutons (Fig. 4A). The majority of synapses in the grafts were of an asymmetric type and contained round clear vesicles; some axosomatic and axodendritic terminals, making symmetric contacts, contained flat vesicles (Fig. 4B). The typical giant synapses of the mossy fibers were distributed all over the graft, but their maximal concentration was observed in the areas corresponding to the dentate hilus. Some of the giant synapses had extremely complex, tortuous contours. They spread among the elements of neuropil in amoeboid fashion, making multiple synaptic contacts. Numerous protrusions and filopodia of various dimensions spread from them in all directions (Fig. 5A). Some giant boutons contained growth vesicles as well as terminals of usual dimensions.

Giant synapses were usually seen in clusters. As in the normal hippocampus, one bouton might contact several neighboring dendrites or, vice versa, several boutons might contact one dendrite (Fig. 5B). However, in accordance with the paucity of pyramidal neurons in the graft tissue, the typical postsynaptic targets of the mossy terminals, giant excrescenses of the proximal segments of the CA3 pyramidal neurons, were only rarely encountered. Usually giant synapses made contacts with small and medium-sized spines. Many such spines had branched heads and contained ribosomes and polysomes. Some of them, in spite of their moderate size, also contained cisterns of smooth endoplasmic reticulum, multivesicular bodies, mitochondria and vacuoles, which are more typical of giant CA3 spines. The active zones of the mossy synapses in the grafts seemed to be longer (or more continuous) than in the normal hippocampus. The number of desmosome contacts of mossy synapses, with mitochondria concentrated at both sides, also seemed to be increased in the grafted tissue (Figs. 2A, 5B).

Though the continuous growth of the nerve processes and development of additional contact surfaces were generally typical of the grafted tissue, some degenerative changes were also present. Such changes were very seldom seen in the neuronal somata. In only a few pyramidal neurons were vacuolization of nuclei, aggregates of lysosomes and lipofuscine granules present. Such aggregates were localized in otherwise normal-looking cytoplasm (Fig. 6A). In one case, we observed a cell, identified as an interneuron, which had a large microfilamentous inclusion in the cytoplasm and unusual ultrastructure of the mitochondria. Many were dumbbell-shaped with extremely flattened and cristless central areas which lay in parallel to the cisterns of endoplasmic reticulum (Fig. 6B).

Definite degenerative changes were present in only some neuronal processes. These were observed in unmyelinated and myelinated axons and in their synaptic endings. Sometimes unitary electron-dense inclusions were encountered in otherwise normallooking processes. Some processes had large expansions (up to 5-6 $\mu \mathrm{m}$ ) and contained numerous lysosomes of various dimensions, as well as dense and lamellar bodies (Fig. 7A,B). Swollen segments of some axons had increased numbers of 

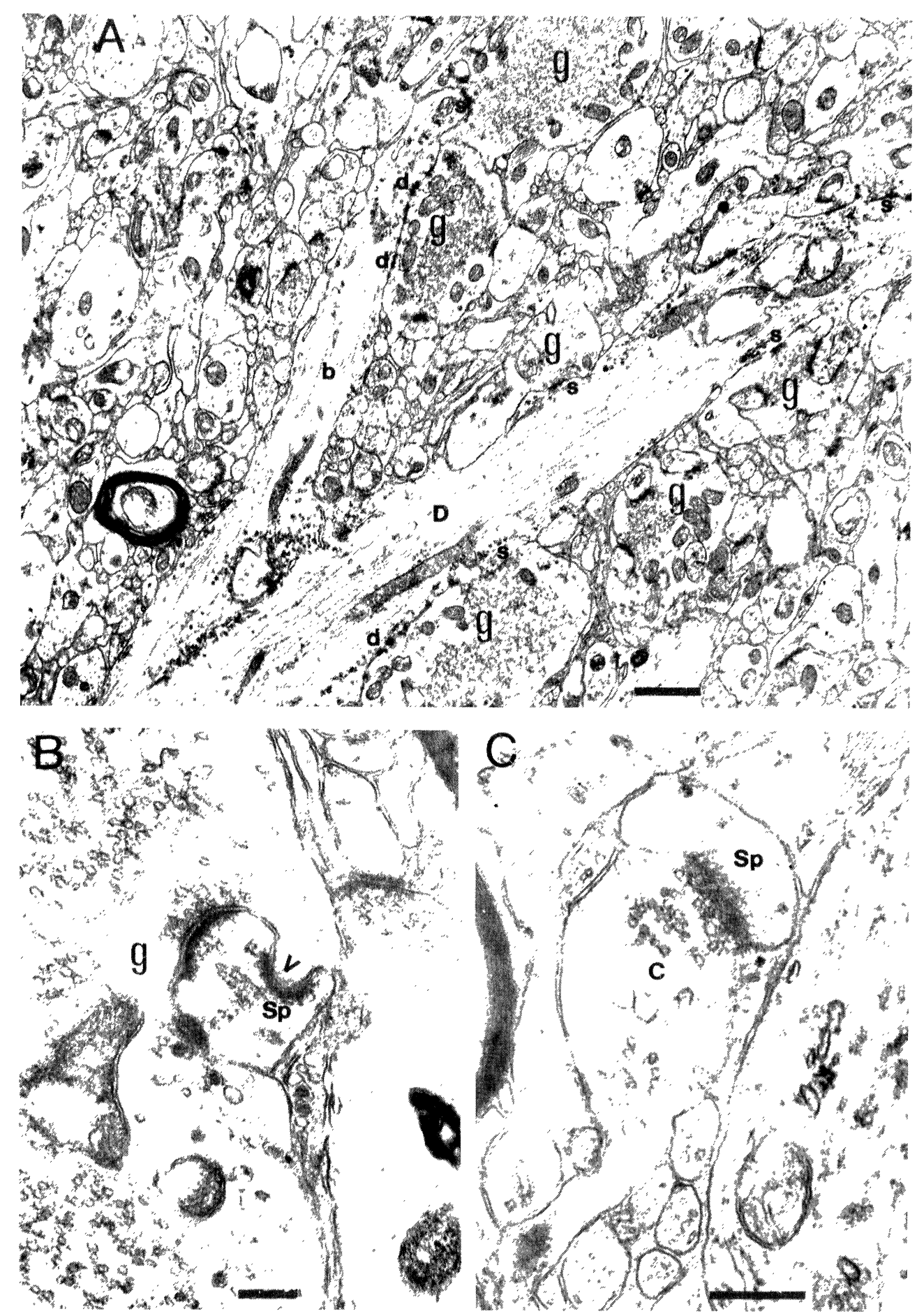

Fig. 2: Signs of continuing growth and development of neuronal processes. A. A parent dendrite (D) with outgrowing short branchlet (b) terminating with a growth tip. Accumulations of endoplasmic reticulum and polysomes are present at the base of the branchlet and in the growth tip. Giant boutons (g) of the mossy fibers make synaptic (s) and desmosome-like (d) contact with the growth tip and surface of the parent dendritc. Bar $1.0 \mathrm{~mm}$. B. Synaptic contacts of a giant bouton (g) with the head of a dendritic spine (Sp) of complex configuration. One of the postsynaptic densities does not have a corresponding accumulation of synaptic vesicles in the apposing presynaptic area (arrowhead). Polyribosomes are present in the spine. Bar $0.25 \mathrm{~mm}$. C. Axonal growth cone (C, presumably of a mossy fiber) making synaptic contact with the head of a dendritic spine (Sp). Empty vacuoles, growth vesicles and a cluster of synaptic vesicles are present in the growth cone. Bar $0.5 \mathrm{~mm}$. 


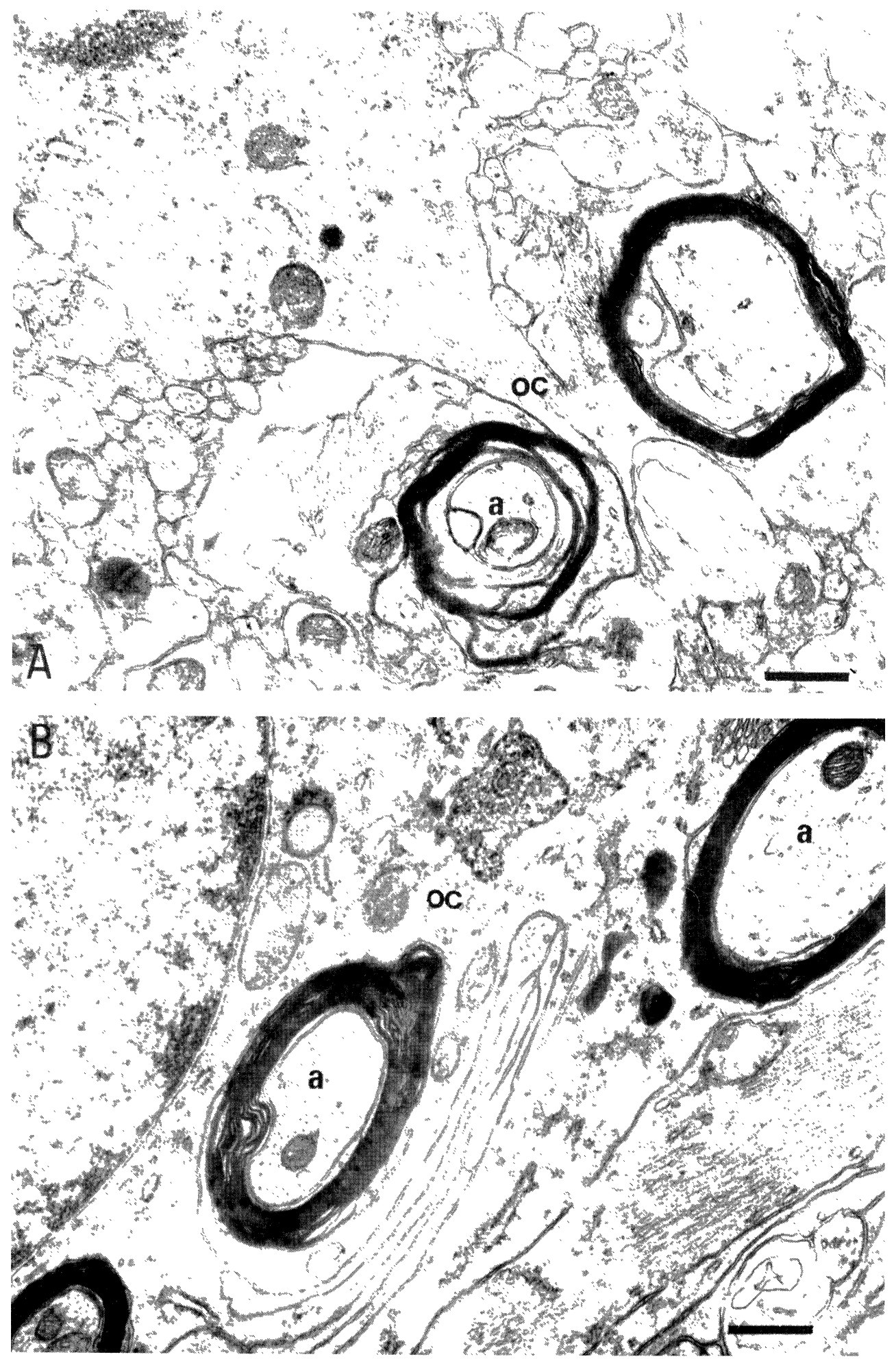

Fig. 3: Continuing myelinization of some axons in the grafted tissuc. A. Axon (a) with a loose myclin sheath. The process of an oligodendrocyte (OC, left upper part of the photo) contacts this axon. Bar $0.5 \mathrm{~mm}$. B. Myelin-producing cell (OC, probably immature oligodendrocyte) with electron-lucid cytoplasm which surrounds myelinated axons (a). A cytoplasmic process of the cell continues into the external lamella of the myclin sheath; several additional thin processes partly envelop the axon. Bar $0.5 \mathrm{~mm}$. 

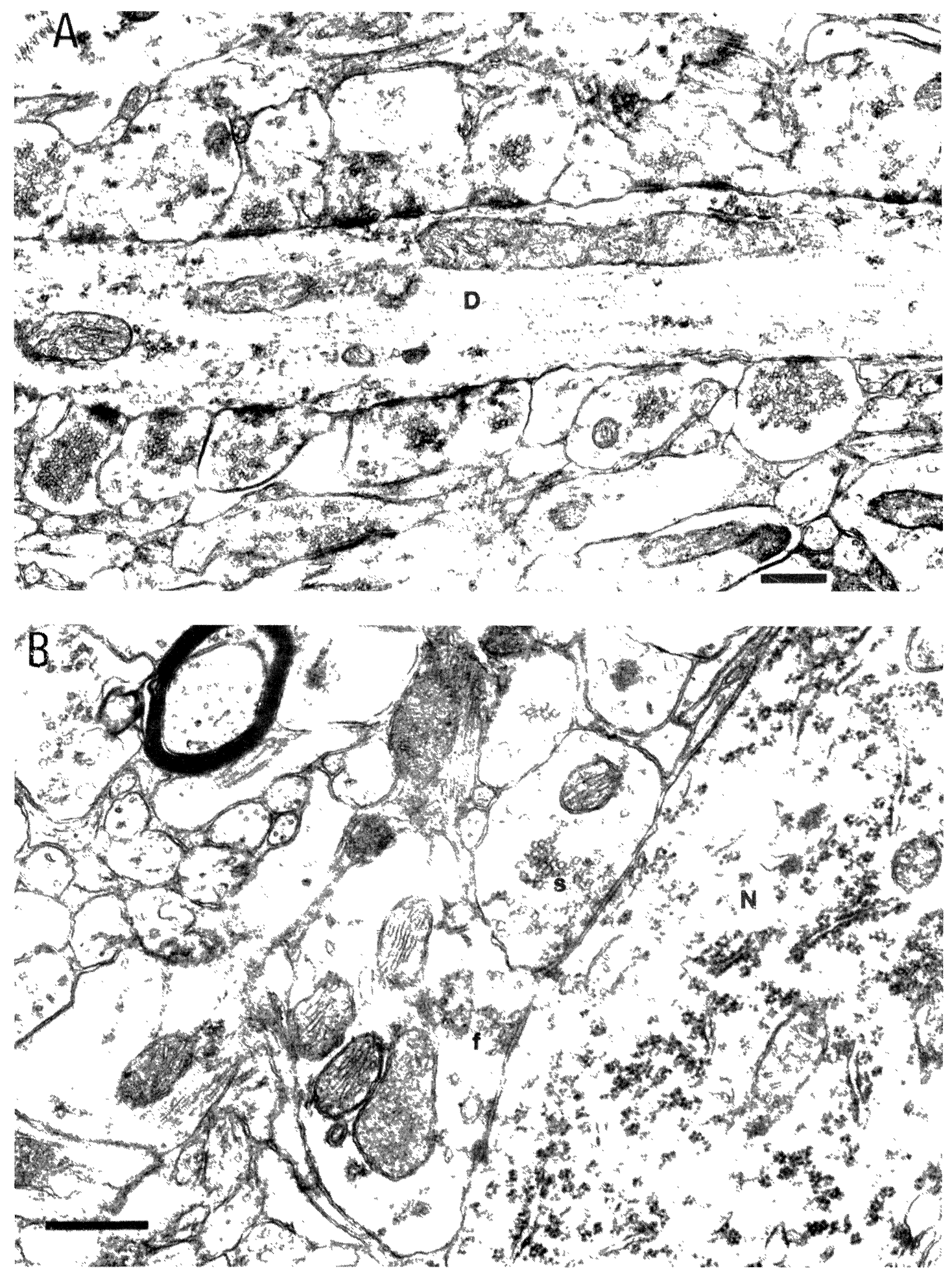

Fig. 4: Synaptic boutons in the grafted dentate tissuc. A. A dendrite (D) studded with synaptic boutons of various dimensions. Bar $0.5 \mathrm{~mm}$. B. A neuron $(\mathrm{N})$ with axosomatic synapses containing spherical clear (s) and flat (I) vesicles (both contacts seem to be of a symmetric type). Bar $0.5 \mathrm{~mm}$. Some synaptic boutons in $\mathbf{A}$ and $\mathbf{B}$, besides typical synaptic vesicles, contain larger empty, presumably growth, vesicles. 

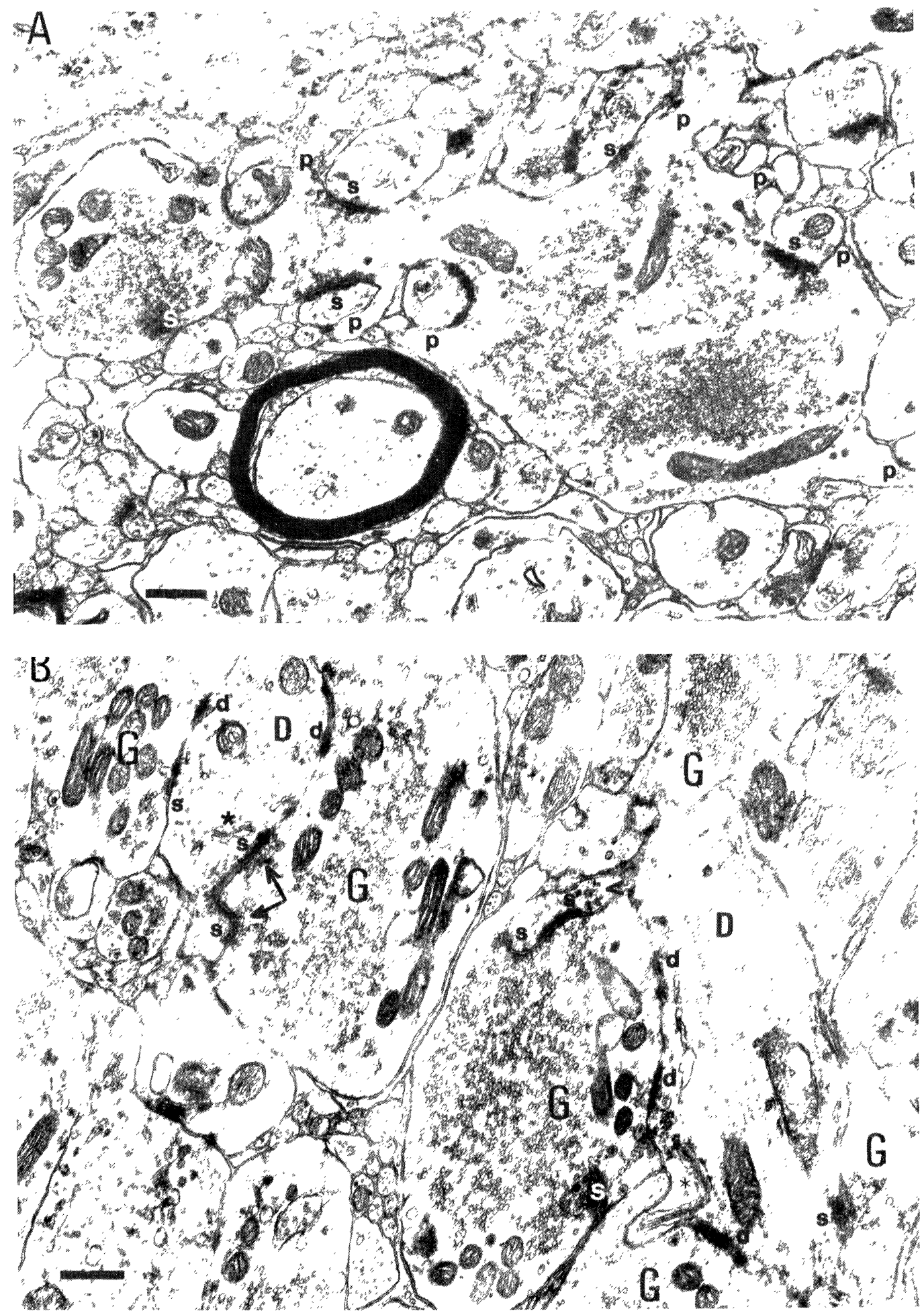

Fig. 5: Giant synapses of mossy fibers in intracortical dentate grafts. A. A single giant bouton of a very complex configuration, with multiple amocboid protuberances $(\mathrm{p})$ and synaptic contacts $(\mathrm{s})$. Bar $0.5 \mathrm{~mm}$. B. A group of giant boutons $(\mathrm{G})$ with synaptic (s) and desmosome-like (d) contacts. Note the long active zonc continuing from the parent dendrite to its spine (arrow). Aggregates of cisterns of agranular reticulum, resembling spine apparatus (asterisks) are present in some dendrites (D). One such aggregate enters from the parent dendrite into its protuberance. A group of ribosomes is seen in onc of the spines (arrowhead). Bar $0.5 \mathrm{~mm}$. 

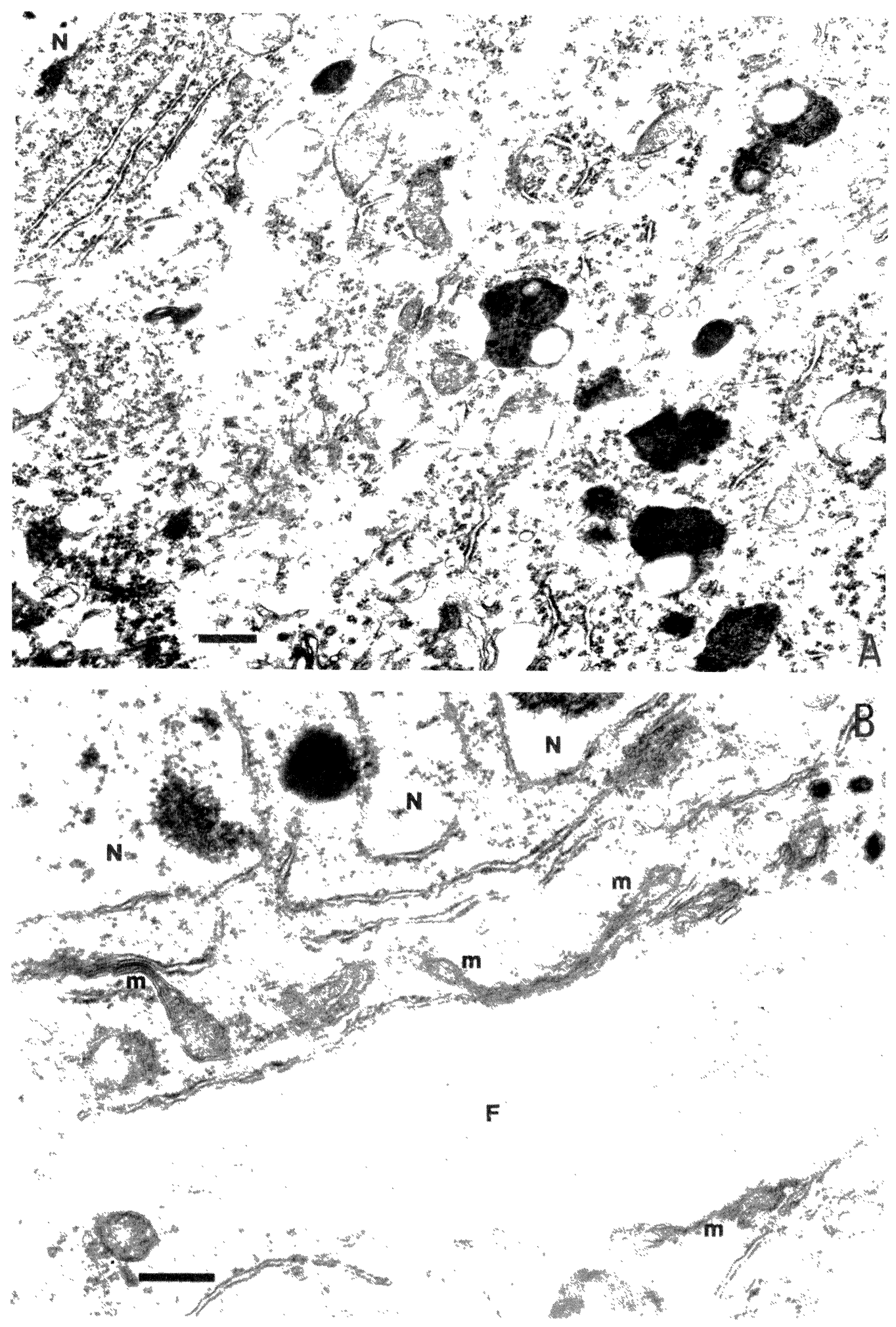

Fig. 6: Signs of degeneration in some neurons of the grafted tissuc. A. A local group of lysosomes and autophagic vacuoles present in the otherwise morphologically normal pyramidal neuron ( $\mathrm{N}$ - nucleus). Bar $0.5 \mathrm{~mm}$. B. A presumably inhibitory interncuron with lobulated nucleus $(\mathrm{N})$. Its cytoplasm contains a large fasciculus of filaments $(\mathrm{F})$. lysosomes and dumbbell-shaped mitochondria (m). Bar $0.5 \mathrm{~mm}$. 


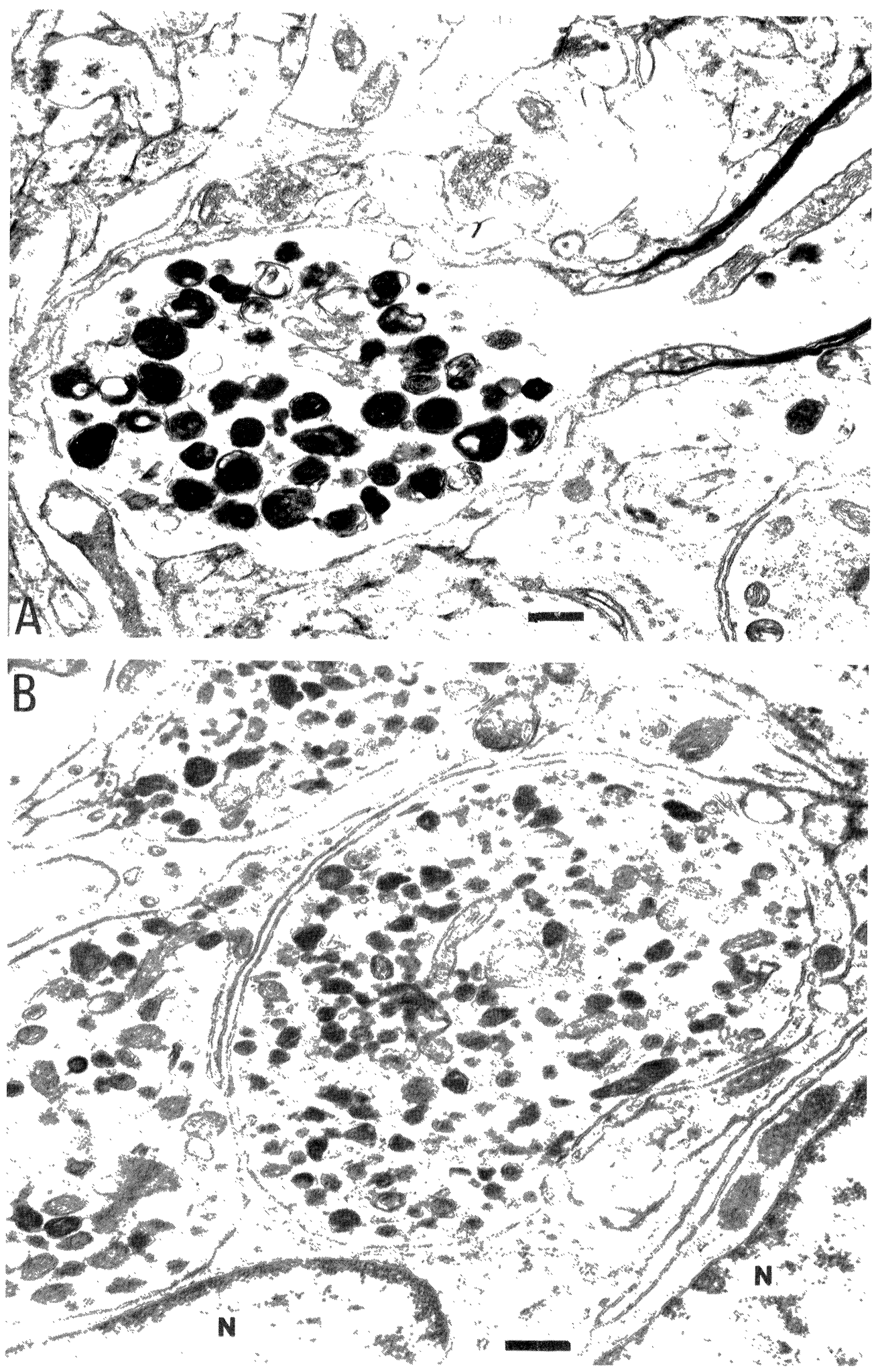

Fig. 7: Signs of degeneration in the neuronal processes. A. Terminal cxpansion of a myelinated axon densely packed with clectron-dense and lamellar bodies. Bar $0.5 \mathrm{~mm}$. B. A group of neuronal processes with degenerative changes adjacent to the graft/host interface. The glial cells with their large nuclei $(N)$ flattened along the border of the graft are scen bclow. Bar $0.5 \mathrm{~mm}$. 
microtubules, sometimes twisted into tangles. In some axonal profiles microtubules were replaced by neurofilaments. Single degenerating profiles were encountered in neuropil, but more often were gathered into clusters with various degrees of expression of destructive processes. Such clusters were usually present near those areas of the graft border which represented a considerable obstacle to the penetration of neuronal processes, i.e. near accumulations of ependymal cells and interface blood capillaries with hypertrophied perivascular glia $/ 40 /$.

Degenerative changes in the dendrites were observed less often. Morphologically they were identical to those in axonal expansions, and in these cases the dendritic nature of a process could be identified only if synaptic active zones were present upon it. In some other cases, degenerating dendrites with lucent, semi-empty cytoplasm containing only unitary mitochondria could be seen. Sometimes dendrites with signs of destructive changes gave rise to thin collateral branchlets with normal cytoplasm and longitudinally oriented microtubules (Fig. 8A)

In many of the processes, indications of degenerative changes co-existed with signs of increased metabolic activity, such as multiple mitochondria, vacuolated and tubular reticulum and polymorph vesicles (Fig. 8B). Some synapses seemed to be in a state of reorganization. Their synaptic and dense core vesicles were not concentrated in the active zones, but were randomly distributed in the periphery of the terminals and partly gathered into dense groups in the central area. Clear vesicles with dimensions corresponding to those of growth vesicles were usually present in these synapses, as well as in adjacent synaptic terminals with normal ultrastructural features (Fig. $8 \mathrm{C})$.

\section{DISCUSSION}

Organotypic histological and ultrastructural features of dentate neurons have been described in homotopic (intrahippocampal) grafts, as well as in heterotopic /31,33/ and intraocular /15,26,27/ transplants. Normally developed typical neuronal elements, easily identifiable by their ultrastructural characteristics, were also present in the intracortical dentate grafts analyzed in the present paper. We have previously shown that the grafts were interconnected with the surrounding host neocortex by multiple axonal and dendritic processes, crossing the graft/host interface $/ 40 /$, and that synaptic contacts were established between the two tissues /41/. In spite of the graft integration with the host brain, some features, such as the presence of various protuberances, indentations and filopodia on somatic and dendritic membranes, suggest certain deficits of afferentation resulting in the development of additional contact surfaces by the grafted neurons. However, a comparison of intracortical integrated grafts with isolated intraocular grafts shows that the presence of contact with surrounding brain tissue significantly ameliorates these deviations from normal structure. Fully developed somatic spines with postsynaptic densities, long-thin spines upon dendrites and overproduction of dendritic spines, which were described in the intraocular grafts $/ 15,37 /$ and in isolated intrabrain grafts $/ 3 /$, were not obvious in our material.

The mossy fibers which constitute the bulk of the axons of the grafted dentate tissue penetrated into the host neocortex and established synaptic contacts with its neurons $/ 4 /$, but many of them terminated in the graft itself. As mossy fibers normally make contacts en passant and make collateral synapses with polymorph hilar cells and inhibitory interneurons $/ 7,14,24,34 /$, some of the normal targets could be used as postsynaptic elements. However, the paucity in the grafted tissue of the main target elements for mossy fibers, the large CA3 pyramidal neurons, resulted in giant terminal boutons making contact with small and medium-sized spines. In spite of their moderate size, such spines contacted by giant boutons often had branched heads and contained various organelles typical of giant thorny excrescenses. This may indicate the role of mossy terminals in induction of the corresponding features in the postsynaptic target. Such a role for the mossy terminal synaptic boutons has been suggested by some authors $123,35 /$. However, it should be noted that, in isolated (without dentate) intraocular hippocampal grafts, we have observed thorny excrescences of the CA3 pyramidal neurons contacted by several ordinary small synaptic boutons $/ 38 /$. 

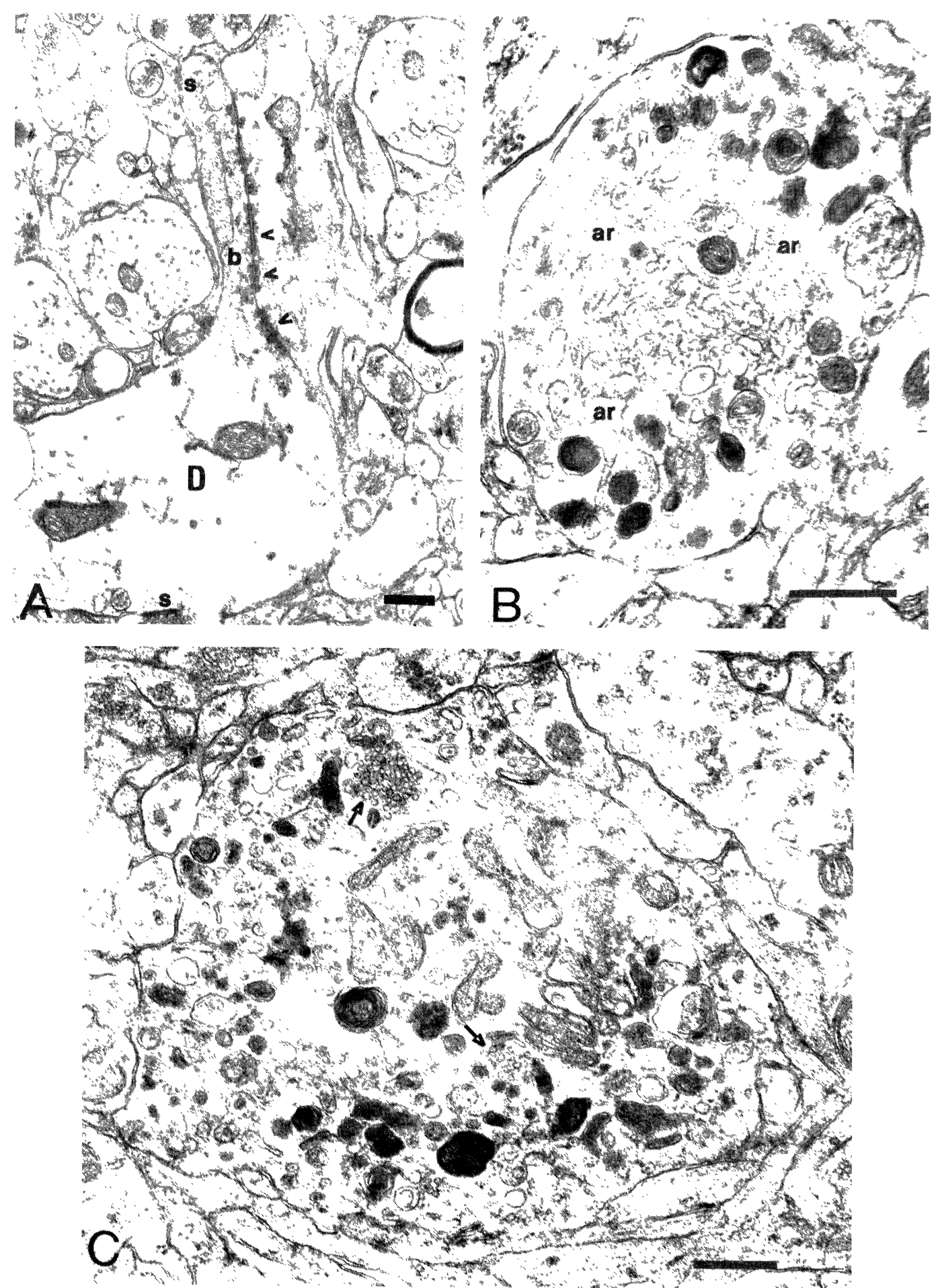

Fig. 8: Ultrastructural signs of a combination of degenerative and reparative processes. A. A semi-cmpty, electron lucid profile of a dendrite (D) from which a thin collateral branch (b) with normal structure emerges. Neighboring neuropil elements make synaptic (s) and desmosome-like (arrowheads) contacts with them. Bar $0.5 \mathrm{~mm}$. B. A neuronal process with lysosomes and lamellar bodies. A large aggregate of vacuoles of agranular endoplasmic reticulum (ar) is present. Bar 0.5 mm. C. Axonal expansion with a large accumulation of mitochondria in the central part. Its peripheral part contains vacuoles and vesicles of various dimensions and electron densities; among them are growth, dense-core and synaptic vesicles. Two groups of synaptic vesicles are indicated by arrows. Bar $0.5 \mathrm{~mm}$. 
The grafted dentate tissue surviving for nine months in the host neocortex seemed to exist in an unstable, dynamic state. Neuronal processes seemed to continue growth and sprouting, as shown by the presence of thin dendritic branchlets with growth tips and axonal growth cones in the tissue. Accumulations of polyribosomes at the base of dendritic spines, which are often encountered in the grafted tissue, have been described in normal dentate and neocortex during early postnatal ontogenesis $/ 17,30 /$ and in the course of regeneration $/ 29 /$ In addition, continuing myelinization with participation of the cells identified as immature oligodendrocytes was present in the grafted tissue. Prolonged and incomplete maturation of the grafted neurons has been noted by several authors both at the ultrastructural $/ 19,26 /$ and functional $/ 21,36 /$ levels. The signs of continuous development were more expressed in the isolated intraocular grafts $/ 26,39 /$ than in the integrated intracerebral ones.

In contrast, degenerative manifestations were also traced in the nine month-old dentate grafts. Dense and lamellar bodies, lysosomes, lypofuscine granules, and changes of cytoskeleton with microtubules twisted into tangles or replaced by neurofilaments were present in degenerating axons. Similar, but more pronounced, degenerative changes, often invading neuronal somata, have been described mainly in non-integrated grafts of brain tissue: in intraocular grafts $/ 38 /$, in tissue transplanted into peripheral nerve $/ 11 /$, in extraparenchymal grafts under cerebellar tentorium $/ 10 /$, and in intraparenchymal grafts. In the last case, failure to previously lesion the recipient's corresponding neuronal systems has been shown to restrict brain/graft integration $/ 16 /$. These changes, which sometimes have been interpreted as evidence of accelerated aging of the grafted brain tissue /16/, may result from the development of the graft as a "closed system", without sufficient exchange of nerve fibers with the host brain. This is partly supported by the stronger expression of such degenerative changes close to areas of graft/host interface which are not permissive for passage of growing neuronal processes.

The described features of the grafted tissue are not qualitatively different from those which can be seen in normal age-matched brain tissue; this is especially true of the dentate fascia. It has been shown in rodents that generation of granular cells and growth of their processes occurs throughout life $15,9,20,28 /$. Growth and sprouting of dentate dendritic processes, together with degenerative changes, occur even in very old humans $16,12,18,25 /$. Damage to and loss of the afferents result in active growth of mossy fibers and synaptogenesis in adult animals /2,13/. Various conditions leading to neuronal death and degeneration of their processes (aging, epilepsy, etc.) reactivate the development of remaining neural elements with many of the features described in the dentate grafts (axonal growth, filopodia-like structures, proliferation of dendrites) $/ 1,4,8,32 /$.

Thus, the observed ultrastructural evidence for continuous development, degeneration and increased reparation in the grafted dentate tissue cannot, on the whole, be regarded as pointing to a pathological state. However, as brain tissue which has survived for nine months is already beyond the period of active development but is still young enough for degeneration associated with aging, the developmental/degenerative changes observed in the grafted dentate are definitely much more strongly expressed than in chronologically matched tissue in situ.

\section{REFERENCES}

1. Altrup U, Speckmann EJ. Epileptic discharges induced by pentylentetrazol: changes of shape of dendrites. Brain Res 1988; 456: 401-405.

2. Anderson KJ, Scheff SW, DeKosky ST. Reactive synaptogenesis in hippocampal area CAl of aged and young adult rats. J Comp Neurol 1986; 252: 374-384.

3. Alvorado-Mallart RM, Sotelo C. Differentiation of cerebellar anlage heterotopically transplanted to adult rat brain: a light and electron microscopic study. J Comp Neurol 1982; 212: 247-267.

4. Babb TL, Kupfer WR, Pretorius JK, Crandall PH, Levesque MF. Synaptic reorganization by mossy fibers in human epileptic fascia dentata. Neuroscience 1991; 42: 351-363.

5. Bayer SA, Yackel JW, Puri PS. Neurons in the rat dentate gyrus granular layer substantially increase during juvenile and adult life. Science 1982; 216: 890892

6. Bertoni-Freddari C, Fattoretti P, Casoli T, Meier-Ruge W, Ulrich Y. Morphological adaptive response of the 
synaptic junctional zones in the human dentate gyrus during aging and Alzheimer's disease. Brain Res 1990; 517: 69-75.

7. Claiborne BJ, Amaral DG, Cowan WM. A light and electron microscopic analysis of the mossy fibers of the rat dentate gyrus. J Comp Neurol 1986; 246: 435-458.

8. Coleman PD, Flood DG. Is dendritic proliferation of surviving neurons a compensatory response to loss of neighbours in the ageing brain? In: Finger S, LeVere TE, Almili CR, Stein DG, eds, Brain Injury and Recovery. New York, London: Plenum Press, 1988; 235-247.

9. Crespo D, Stanfield BB, Cowan WM. Evidence that late-generated granule cells do not simply replace earlier formed neurons in the rat dentate gyrus. Exp Brain Res 1986; 62: 541-548.

10. Das GD. Extraparenchymal neural transplants: cytology and survivability. Brain Res 1983; 241: 182-186.

11. Doering LC, Aguayo AJ. Hirano bodies and other cytoskeletal abnormalities develop in fetal rat CNS grafts isolated for long periods in peripheral nerve. Brain Res 1987; 401: 178-184.

12. Flood DG, Buell SJ, Horwitz GJ, Coleman PD. Dendritic extent in human dentate gyrus granule cells in normal aging and senile dementia. Brain Res 1987; 402: 205-216.

13. Frotscher M, Zimmer J. Lesion-induced mossy fibers to the molecular layer of the rat fascia dentata: identification of postsynaptic granule cells by the Golgi-EM technique. J Comp Neurol 1983; 215: 299311.

14. Frotscher M. Mossy fiber synapses on glutamatedecarboxylase-immunoreactive neurons: evidence for feed-forward inhibition in the CA3 region of the hippocampus. Exp Brain Res 1989; 75: 441-445.

15. Goldowitz D, Seiger A, Olson L. Anatomy of the isolated area dentata grown in the rat anterior eye chamber. J Comp Neurol 1982; 208: 382-400.

16. Gopinath G, Shetty AK, Tandon PN. Ageing changes in the transplants of fetal substantia nigra grafted to striatum of adult rat. Neuroscience 1991; 40: 429-443.

17. Greenough WT, Hwong HMF, Gorman C. Evidence for active synapse formation or altered postsynaptic metabolism in visual cortex of rats reared in complex environments. Proc Natl Acad Science USA 1985; 82: 4549-4552.

18. Ihara Y. Massive somatodendritic sprouting of cortical neurons in Alzheimer's disease. Brain Res 1988; 459: 138-144.

19. Jaeger CB. Cytoarchitectonics of substantia nigra grafts: A light and electron microscopic study of immunocytochemically identified dopaminergic neurons and fibrous astrocytes. J Comp Neurol 1985: 231: 121135.

20. Kaplan MS, Bell DH. Neuronal proliferation in the 9 month-old rodent - radioautographic study of granule cells in the hippocampus. Exp Brain Res 1983; 52: 15.

21. Mudrick LA, Stabel J, Jones RSG, Heinemann U. Prolonged electrophysiological maturation of transplanted hippocampal neurons. Brain Res 1990; 524: 331-335.

22. Raisman G, Morris RJ, Zhou CF. Specificity of the reinnervation of adult hippocampus by embryonic hippocampal transplants. Prog Brain Rəs 1987; 71: 325-333

23. Represa A, Dessi F, Beaudoin M, Ben-Ari J. Effects of neonatal irradiation on rat hippocampus: I. Postnatal maturation of hippocampal cells. Neuroscience 1991; 42: 137-150.

24. Ribak CE, Seress L. A Golgi-electron microscopic study of fusiform neurons in the hilar region of the dentate gyrus. J Comp Neurol 1988; 271: 67-78.

25. Ruiter De JP, Uylings HBM. Morphometric and dendritic analysis of fascia dentata granule cells in human aging and senile dementia. Brain Res 1987; 402: 217-229

26. Sorensen T, Zimmer J. Ultrastructural organization of normal and transplanted rat fascia dentata: I. A qualitative analysis of intracerebral and intraocular grafts. J Comp Neurol 1988; 267: 15-42.

27. Sorensen T, Zimmer J. Ultrastructural organization of normal and transplanted rat fascia dentata: II. A quantitative analysis of the synaptic organization of intracerebral and intraocular grafts. J Comp Neurol 1988; 267: 43-54.

28. Stanfield BB, Trice JE. Evidence that granule cells generated in the dentate gyrus of adult rats extend axonal projections. Exp Brain Res 1988; 72: 399-406.

29. Steward O. Regulation of synaptogenesis through the local synthesis of protein at the postsynaptic site. Prog Brain Res 1987; 71: 267-279.

30. Steward O, Falk PM. Selective localization of polyribosomes beneath developing synapses: a quantitative analysis of the relationships between polyribosomes and developing synapses in the hippocampus and dentate gyrus. J Comp Neurol 1991; 314: 545-557.

31. Sunde NA, Zimmer J. Cellular, histochemical, and connective organization of the hippocampus and fascia dentata transplanted to different regions of immature and adult rat brains. Dev Brain Res 1983; 8: 165-192.

32. Sutula T, Xiao-Xian H, Cavazos J, Scott G. Synaptic reorganization in the hippocampus induced by abnormal functional activity. Science 1988; 239: 11471150.

33. Suzuki M. Transplantation of hippocampal anlagen into cerebella of adult rats. Psychiat Neurol (Jap) 1986; 88: 471-487.

34. Tombol T, Somogyi F, Hajdu F, Madarasz M. Granule cells, mossy fibers and pyramidal neurons: an electron microscopic study of the cat's hippocampal formation. Acta Morphol Hung 1978: 26: 291-310. 
35. Vijayan VK. Morphogenesis of the mossy fiber synapses in the hippocampus of the Rhesus monkey. Dev Brain Res 1986; 25: 259-270.

36. Walsh JP, Zhou FC, Hull CD, Fischer RS, Levine MS, Buchwald NA. Physiological and morphological characterization of striatal neurons transplanted into the striatum of adult rats. Synapse $1988 ; 2: 37-44$.

37. Zhuravleva ZN, Bragin AG, Vinogradova OS. Organization of the nervous tissue (hippocampus and septum) developing in the anterior eye chamber. II. Neuronal perikarya and dendritic processes. J Hirnforschung 1985; 26: 419-437.

38. Zhuravleva ZN, Bragin AG, Vinogradova OS. Organization of the nervous tissue (hippocampus and septum) developing in the anterior eye chamber. III. Axonal processes and synaptic endings. J Hirnforschung 1986; 27: 323-341.

39. Zhuravleva ZN, Vinogradova OS, Bragin AG Incomplete maturation of the nervous tissue transplanted into the anterior eye chamber. in: Trogan $S$, Stastny F, eds, Ontogenesis of the Brain. Praha $1987 ; 4: 67-70$

40. Zhuravleva $\mathrm{ZN}$. Intracortical dentate fascia grafts in the adult rat hosts. Ultrastructure of the graft/host interface. J Hirnforschung 1991; 32: 384-397.

41. Zhuravleva $\mathrm{ZN}$, Vinogradova OS. Intracortical dentate fascia grafts: mossy fiber synapses in the host neocortex. J Neur Transplant Plast 1994; 5: 169-182. 

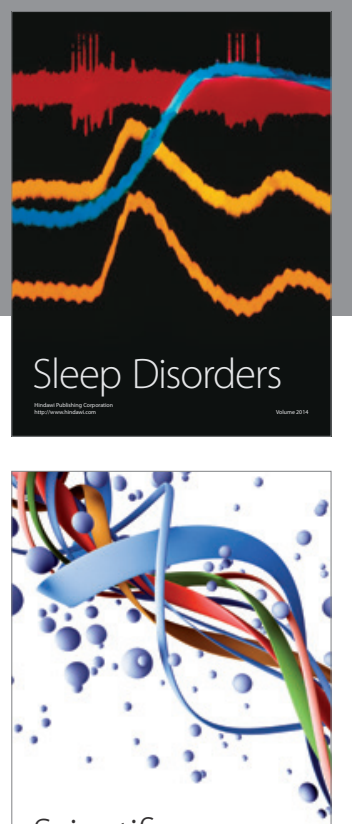

Scientifica
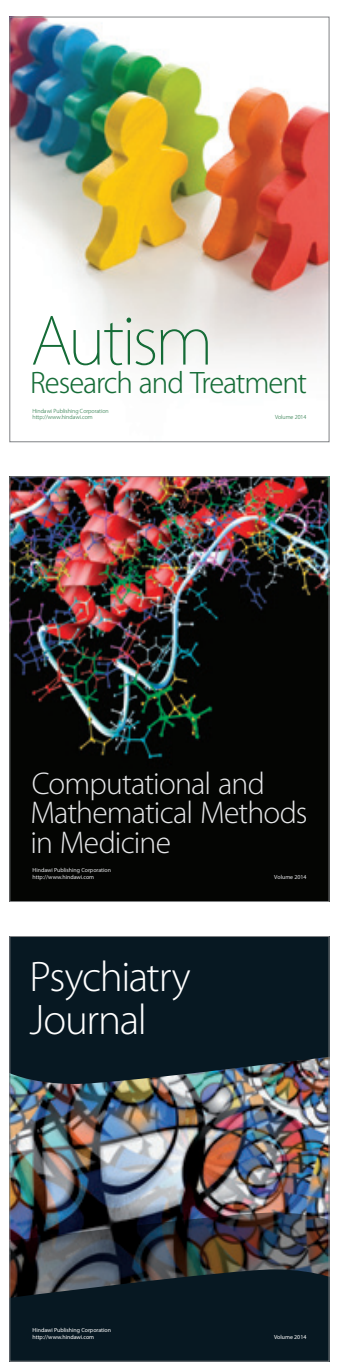
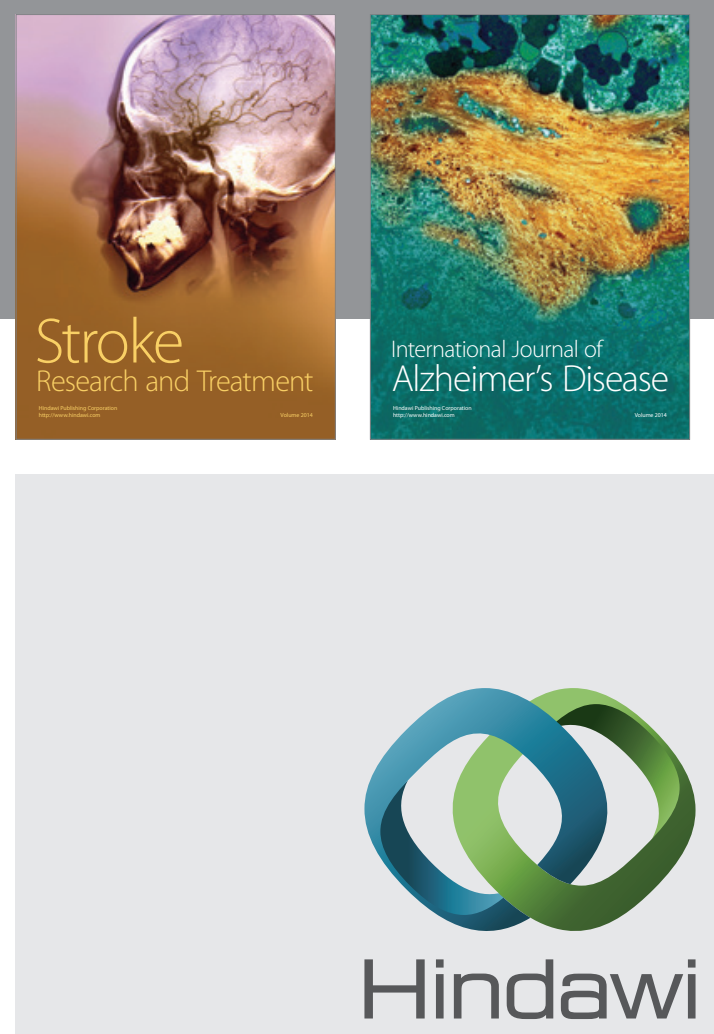

Submit your manuscripts at

http://www.hindawi.com
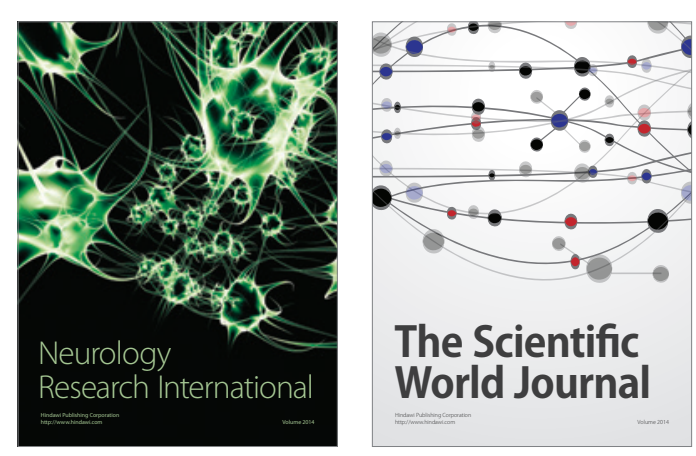

The Scientific World Journal

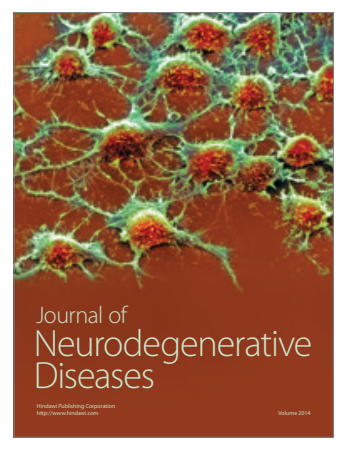

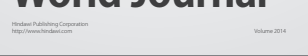

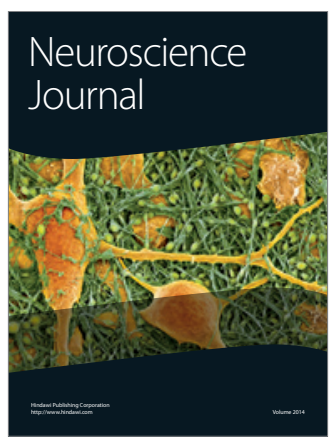

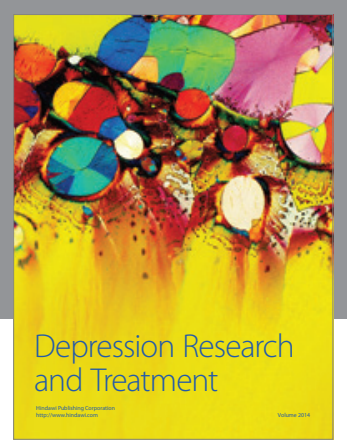
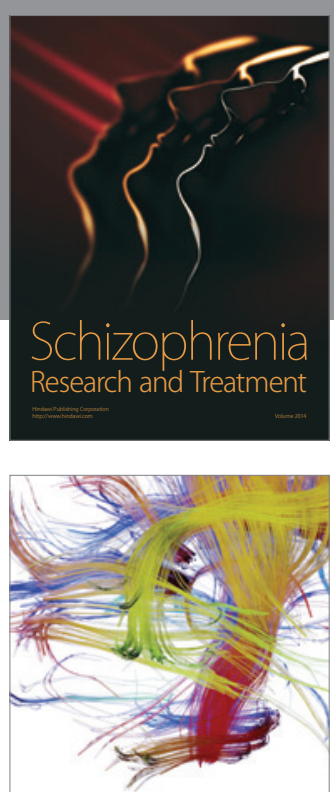

Brain Science

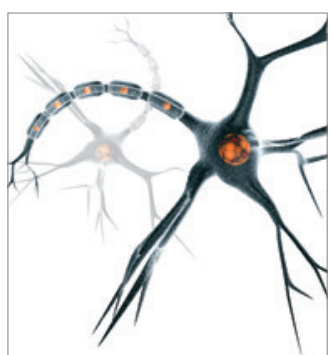

Neural Plasticity
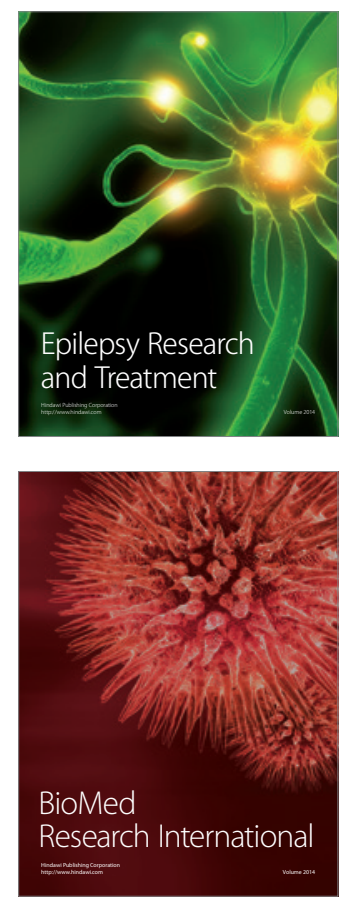

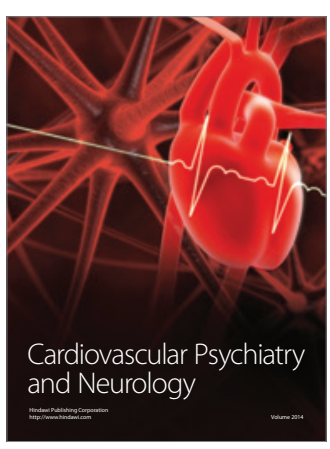

Parkinson's

Disease
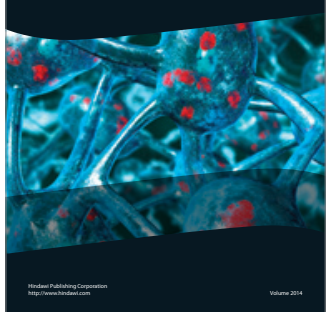